\title{
Non-PSEUDO-AntiBiotiCs Score-A Predictor of Bacteraemia Caused by Pseudomonas aeruginosa. A Case-control Study
}

\section{Kaori Iwami}

St. Luke's International Hospital

Takahiro Matsuo ( $\nabla$ tmatsuo@luke.ac.jp )

St. Luke's International Hospital

Kuniyoshi Hayashi

St. Luke's International University

Nobuyoshi Mori

St. Luke's International Hospital

\section{Research Article}

Keywords: Pseudomonas aeruginosa, bacteraemia, Non-PSEUDO-AntiBiotiCs score

Posted Date: April 22nd, 2021

DOl: https://doi.org/10.21203/rs.3.rs-408340/v1

License: (c) (i) This work is licensed under a Creative Commons Attribution 4.0 International License. Read Full License 


\section{Abstract}

Background: Immoderate use of broad-spectrum antimicrobials could lead to emergence of resistant bacteria. The purpose of this study was to identify factors associated with Pseudomonas aeruginosa bacteraemia and develop an exclusion scoring system to help clinicians select an appropriate antimicrobial treatment.

Methods: This single-centre case-control study recruited inpatients and outpatients (age $\geq 20$ years) with P. aeruginosa or Escherichia coli bacteraemia at St. Luke's International Hospital in Tokyo from April 2005 to March 2020. Bivariate associations were assessed using $\chi^{2}$ test, Fisher's exact test, or Mann-Whitney $U$ test, and the relationship between $P$. aeruginosa bacteraemia and other variables was determined using multivariable logistic regression analysis.

Results: A total of 1562 patients (208 patients with P. aeruginosa bacteraemia and 1354 patients with $E$. coli bacteraemia) were included. Multivariable analysis revealed 11 variables associated with $P$. aeruginosa bacteraemia: Nosocomial infections, Pneumonia, Sex (males), Exposure to antibiotics within 90 days, Urinary tract infection, Urinary catheterization, abDOminal infection, Age $<77$ years, Body mass index $<19$, presence of Central venous catheter, and Central line-associated bloodstream infection/peripheral line-associated bloodstream infection; these variables were used to develop the NonPSEUDO-AntiBiotiCs score. The area under the receiver operating characteristic curve was 0.89 (95\% confidence interval: $0.88-0.92$ ), and the best cut-off-point was 5; a score of $\geq 5$ had a sensitivity of $80 \%$ and a specificity of $83 \%$.

Conclusion: We developed the Non-PSEUDO-AntiBiotiCs score. This score may allow clinicians to rule out the possibility of $P$. aeruginosa bacteraemia and prevent the abuse of broad-spectrum antimicrobials.

\section{Background}

Pseudomonas aeruginosa bacteraemia (PAB) has a higher mortality rate (29\%) [1] than bacteraemia caused by other gram-negative rods, such as Escherichia coli and Klebsiella spp. [2]. P. aeruginosa is an innately antibiotic-resistant microorganism, and its toxicity mechanisms have been shown to be associated with restricted permeability of the cell wall, enhanced activity of the efflux system, and presence of the ampC gene for inducible chromosome beta-lactamase [3]. Empiric antimicrobial treatment failure is known to result in higher mortality rates in both community-acquired and nosocomial infections [4]. Therefore, clinicians often need to determine whether $P$. aeruginosa is a causative organism based on previously reported risk factors.

Notably, the abuse of broad-spectrum antimicrobials for treating $P$. aeruginosa could lead to emergence of resistant bacteria and an increase in adverse events [5]. Because inadequate empirical treatment is related to all-cause mortality and infection-related mortality due to PAB [1], appropriate and prompt antimicrobial treatments are essential for the management of PAB. Risk factors for PAB have already been identified and include male sex [1, 6, 7], haemodialysis [1, 7], solid organ transplants [1], cancer [1], 
human immune deficiency virus infection [1], diabetes [8], neutropenia [6, 7, 9], haematological malignancy $[7,9,10]$, central venous catheter [11, 12], healthcare-associated infection $[7,11]$, prior hospital admission [7], and prior antimicrobial use [12,13]. Although these factors are useful for suspecting the presence of $\mathrm{PAB}$, to the best of our knowledge, no scoring systems are available to help clinicians rule out the possibility of PAB. Therefore, the purpose of this study was to identify factors associated with $\mathrm{PAB}$ and develop an exclusion score system that will assist in clinical practice.

\section{Methods}

\section{Study Aim and Design}

This study aimed to identify factors associated with Pseudomonas aeruginosa bacteraemia and develop an exclusion scoring system to help clinicians select an appropriate antimicrobial treatment. A retrospective, single-centre, case-control study was performed at St. Luke's International Hospital (a 520bed hospital) in Tokyo, Japan, between April 2005 and March 2020.

\section{Inclusion and Exclusion Criteria}

Inpatients and outpatients (age $\geq 20$ years) with PAB or $E$. coli bacteraemia (ECB) were selected from the electronic hospital database based on positive blood culture findings. Patients with $E$. coli detected by blood culture during the corresponding period were included in the control group, and those with multiple bacteraemias were excluded. In addition, in patients with multiple episodes of bacteraemia, only the first episode of bacteraemia was included in the analysis.

\section{Data Collection}

Patient data were extracted from inpatients' and outpatients' electronic medical records. Study variables included patient demographics, comorbidities, probable causes of bacteraemia, presence of foreign bodies, use of immunosuppressive drugs, chemotherapy, antibiotics within 90 days before bacteraemia, hospitalization within 1 year, surgery within 1 year, vital signs, laboratory results and microbiological findings, length of stay, admission to the intensive care unit, and mortality.

\section{Variable Definitions}

PAB and ECB were defined by the laboratory findings of at least one set of positive blood cultures collected using standard sterile techniques [11]. Neutropenia was defined as a neutrophil count of less than $500 / \mathrm{mm}^{3}$ [8]. The source of bacteraemia was comprehensively determined through a review of the electronic discharge summary and the daily chart record of patient symptoms, physical examinations, laboratory results, and radiological findings. A central venous catheter, such as a central venous port catheter, peripherally inserted central catheter, or temporary or permanent catheter for haemodialysis, was defined as an intravascular access device or a catheter whose end is placed in or near the heart or in one of the main veins $[8,14,15]$. Malignancies included both solid tumours and hematologic malignancies that had been treated with chemotherapy within the last 90 days. Central line-associated bloodstream 
infection (CLABSI) was classified as an infection of central venous catheters and peripherally inserted central venous catheters using the Centres for Disease Control and Prevention definitions [16], and peripheral line-associated bloodstream infection (PLABSI) was defined as bacteraemia with at least one of the following criteria: existence of phlebitis and/or disappearance of clinical symptoms after peripheral line withdrawal, and/or careful exclusion of bacteraemia as another focus $[17,18]$. Intraabdominal infections included cholangitis, cholecystitis, intestinal obstruction, oesophageal varices, appendicitis, diverticulitis, peritonitis, liver abscess, intra-abdominal abscess, and acute pancreatitis. Skin and soft tissue infections included erysipelas, cellulitis, subcutaneous abscess, necrotizing fasciitis, and wound infections. Respiratory diseases included chronic obstructive pulmonary disease (COPD), asthma and COPD overlap syndrome, bronchiectasis, interstitial pneumonia, diffuse panbronchiolitis, and bronchial asthma. Nosocomial infections (healthcare-associated infections) were diagnosed when patients had a positive blood culture after 48 hours of hospitalization. Community-acquired bacteraemia was diagnosed when it occurred in the outpatient setting or within 48 hours of hospitalization; however, patients who fulfilled one or more of the following criteria were categorized as having healthcareassociated infections [11, 19]: 1) underwent intravenous therapy at home or in an outpatient setting within the past 30 days; 2 ) attended a hospital, haemodialysis clinic, or received intravenous chemotherapy within the past 30 days; 3 ) had more than two days of hospitalization in the past 90 days; and 4) spent two or more days in a nursing home or in an assisted living facility in the past 90 days.

\section{Microbiological Tests}

We used the BacT/ALERT 3D system (bioMérieux, Inc.) for blood cultures and the MicroScan WalkAway 96PLUS (Beckman Coulter, Tokyo, Japan) for susceptibility testing.

\section{Statistical Analyses}

In bivariate associations, we used the chi-square or Fisher's exact test for categorical variables and the Mann-Whitney $U$ test for continuous variables. Variables significantly associated with PAB in univariate analysis were applied to the CART model as a part of the multivariable analysis after removing highly correlated explanatory variables in terms of the variance inflation factor for multicollinearity. For continuous variables, those that were statistically significant in univariate analysis were converted into binary categorical variables using the CART model. As a result, variables that appeared at higher branch levels in the tree of the CART model and those that were clinically important among variables that were statistically significant in univariate analysis were included as explanatory variables in the multivariate logistic regression analysis. The final explanatory variables of the model were selected by the forward stepwise approach. The receiver operating characteristic (ROC) curve was plotted with the model, and the values of the cut-off-point and area under the ROC curve were calculated from this ROC curve.

The statistical significance threshold was set at $P<0.05$. All statistical analyses were carried out using the statistical software program SPSS 19.0J (IBM Japan, Tokyo, Japan) and EZR (Saitama Medical Center, Jichi Medical University, Saitama, Japan), which is a graphical user interface for R (The R Foundation for Statistical Computing, Vienna, Austria). 


\section{Results}

\section{Study Participants}

Of the 1592 observations, 14 observations (7 patients with both PAB and ECB) were excluded, and the first episodes of bacteraemia of 16 patients with multiple episodes of bacteraemia were included. Ultimately, 1562 patients (208 PAB and 1354 ECB) were included in the study (Fig. 1). Comparisons of demographic characteristics, comorbidities, and site of infection between the PAB and ECB groups are shown in Table 1. Patients with PAB were younger (72 years versus 76 years, $p<0.001)$ and less obese $(19.7 \%$ versus $21.7, p<0.001)$ and had higher proportions of males $(68.3 \%$ versus $40.5 \% ; p<0.001)$, solid tumours $(11.1 \%$ versus $7.0 \% ; p=0.048)$, haematological malignancy $(5.3 \%$ versus $2.1 \% ; p=0.013)$, diabetes $(37.0 \%$ versus $28.7 \% ; p=0.018)$, chronic kidney disease $(12.5 \%$ versus $7.8 \% ; p=0.030)$, haemodialysis ( $12.5 \%$ versus $4.5 \% ; p<0.001)$, and neutropenia ( $5.8 \%$ versus $1.6 \% ; p=0.001)$ than those with ECB. In addition, the PAB group had higher percentages of urinary catheters $(65.4 \%$ versus $22.7 \%$; $p$ $<0.001$ ), central venous catheter (38.5\% versus $9.7 \% ; p<0.001)$, peripherally inserted central venous catheter (PICC) $(4.8 \%$ versus $1.9 \% ; p=0.021)$, and arterial line $(31.7 \%$ versus $9.2 \% ; p<0.001)$ than the ECB group. 
Table 1

Comparison of patient characteristics between Pseudomonas aeruginosa and Escherichia coli bacteraemia groups using univariate analysis

\begin{tabular}{|c|c|c|c|}
\hline & $\begin{array}{l}\text { P. aeruginosa } \\
(\mathrm{n}=\mathbf{2 0 8})\end{array}$ & $\begin{array}{l}\text { E. coli } \\
(n=1354)\end{array}$ & $\begin{array}{l}p \\
\text { values }\end{array}$ \\
\hline Age, median (IQR) & $72(60-79.8)$ & $76(64-84)$ & $<0.001$ \\
\hline Sex (male), n (\%) & $142(68.3)$ & $548(40.5)$ & $<0.001$ \\
\hline BMI, median (IQR) & $\begin{array}{l}19.7(17.4- \\
22.7)\end{array}$ & $21.7(19-24.3)$ & $<0.001$ \\
\hline \multicolumn{4}{|l|}{ Comorbid conditions, n (\%) } \\
\hline Solid tumour & $23(11.1)$ & $95(7.0)$ & 0.048 \\
\hline Haematological malignancy & $11(5.3)$ & $28(2.1)$ & 0.013 \\
\hline Diabetes mellitus & $77(37.0)$ & $388(28.7)$ & 0.018 \\
\hline Chronic kidney disease & $26(12.5)$ & $105(7.8)$ & 0.030 \\
\hline Haemodialysis & $26(12.5)$ & $61(4.5)$ & $<0.001$ \\
\hline Peritoneal dialysis & $1(0.5)$ & $3(0.2)$ & 0.436 \\
\hline Neutropenia & $12(5.8)$ & $22(1.6)$ & 0.001 \\
\hline Respiratory disease & $30(14.4)$ & $172(12.7)$ & 0.505 \\
\hline \multicolumn{4}{|l|}{ Predisposing condition, n (\%) } \\
\hline Urinary catheterization & $136(65.4)$ & $308(22.7)$ & $<0.001$ \\
\hline Presence of central venous catheter & $10(25)$ & $14(24.1)$ & $<0.001$ \\
\hline $\begin{array}{l}\text { Presence of peripherally inserted central venous } \\
\text { catheter }\end{array}$ & $10(4.8)$ & $26(1.9)$ & 0.021 \\
\hline Arterial line & $66(31.7)$ & $124(9.2)$ & $<0.001$ \\
\hline Venous line & $175(84.1)$ & $518(38.3)$ & $<0.001$ \\
\hline Use of a mechanical ventilator & $30(14.4)$ & 49 (3.6) & $<0.001$ \\
\hline Tracheal intubation & $30(14.4)$ & $38(2.8)$ & $<0.001$ \\
\hline \multicolumn{4}{|l|}{$\begin{array}{l}\text { Primary site of infection (source of bacteraemia), } n \\
(\%)\end{array}$} \\
\hline Urinary tract infection & $67(32.2)$ & $881(65.1)$ & $<0.001$ \\
\hline \multicolumn{4}{|c|}{$\begin{array}{l}\text { Abbreviations: IQR, interquartile range; } \mathrm{BMI} \text {, body mass index; } \mathrm{CLABSI} \text {, central line-associated } \\
\text { bloodstream infection; PLABSI, peripheral line-associated bloodstream infection; } \mathrm{SpO}_{2} \text {, oxygen } \\
\text { saturation measured by a pulse oximeter; } \gamma \text {-GTP, } \gamma \text {-glutamyl transpeptidase; } C R P, C \text {-reactive protein. }\end{array}$} \\
\hline
\end{tabular}




\begin{tabular}{|c|c|c|c|}
\hline & $\begin{array}{l}\text { P. aeruginosa } \\
(\mathrm{n}=\mathbf{2 0 8})\end{array}$ & $\begin{array}{l}\text { E. coli } \\
(n=1354)\end{array}$ & $\begin{array}{l}p \\
\text { values }\end{array}$ \\
\hline Abdominal Infection & $35(16.8)$ & $335(24.7)$ & 0.016 \\
\hline Pneumonia & $67(32.2)$ & $36(2.7)$ & $<0.001$ \\
\hline CLABSI/PLABSI & $13(6.3)$ & $3(0.2)$ & $<0.001$ \\
\hline Skin and soft tissue & $5(2.4)$ & $9(0.7)$ & 0.037 \\
\hline Unknown and others & $21(10.1)$ & $90(6.6)$ & 0.097 \\
\hline \multicolumn{4}{|l|}{ Drug use within the prior 90 days, $n(\%)$} \\
\hline Steroid & $72(34.6)$ & $189(14.0)$ & $<0.001$ \\
\hline Chemotherapy & $34(16.3)$ & $123(9.1)$ & 0.003 \\
\hline Antibiotics & $172(82.7)$ & $372(27.5)$ & $<0.001$ \\
\hline Hospitalization within the prior 1 year, n (\%) & $78(37.5)$ & $392(29.0)$ & 0.015 \\
\hline Surgery within the prior 1 year, $\mathrm{n}(\%)$ & $89(42.8)$ & $221(16.3)$ & $<0.001$ \\
\hline Nosocomial, n (\%) & $149(71.6)$ & $431(31.8)$ & $<0.001$ \\
\hline \multicolumn{4}{|l|}{ Vital signs, median (IQR) } \\
\hline Systolic blood pressure (mmHg) & $120(104-135)$ & $120(102-138)$ & 0.908 \\
\hline Pulse rate (/minute) & $90(78-108)$ & $88(76-102)$ & 0.173 \\
\hline Respiratory rate (/minute) & $18(16-24)$ & $18(16-23.25)$ & 0.065 \\
\hline Temperature $\left({ }^{\circ} \mathrm{C}\right)$ & $\begin{array}{l}37.3(36.7- \\
38.3)\end{array}$ & $\begin{array}{l}37.7(36.8- \\
38.6)\end{array}$ & 0.003 \\
\hline Oxygen saturation (\%) & $97(95-98)$ & $96(95-98)$ & 0.042 \\
\hline \multicolumn{4}{|l|}{ Laboratory findings, median (IQR) } \\
\hline White blood cell count $\left(\times 10^{3} / \mu \mathrm{L}\right)$ & $9.85(6.2-15.1)$ & $10.5(7-14.4)$ & 0.291 \\
\hline Albumin (g/dL) & $2.85(2.3-3.4)$ & $3.4(2.9-3.8)$ & $<0.001$ \\
\hline Total bilirubin (mg/dL) & $0.7(0.4-1.1)$ & $0.8(0.6-1.5)$ & $<0.001$ \\
\hline Y-GTP (U/L) & $\begin{array}{l}67(29.5- \\
162.5)\end{array}$ & $48(22-148.5)$ & 0.019 \\
\hline Creatine kinase (U/L) & $50(26-112.5)$ & $67(38-136.8)$ & 0.001 \\
\hline \multicolumn{4}{|c|}{$\begin{array}{l}\text { Abbreviations: IQR, interquartile range; } \mathrm{BMI} \text {, body mass index; } \mathrm{CLABSI} \text {, central line-associated } \\
\text { bloodstream infection; PLABSI, peripheral line-associated bloodstream infection; } \mathrm{SpO}_{2} \text {, oxygen } \\
\text { saturation measured by a pulse oximeter; } \gamma-\mathrm{GTP}, \mathrm{\gamma} \text {-glutamyl transpeptidase; CRP, C-reactive protein. }\end{array}$} \\
\hline
\end{tabular}




\begin{tabular}{|c|c|c|c|}
\hline & $\begin{array}{l}\text { P. aeruginosa } \\
(\mathrm{n}=\mathbf{2 0 8})\end{array}$ & $\begin{array}{l}\text { E. coli } \\
(\mathrm{n}=1354)\end{array}$ & $\begin{array}{l}p \\
\text { values }\end{array}$ \\
\hline Calcium (mg/dL) & $8.4(7.7-8.9)$ & $8.8(8.4-9.2)$ & $<0.001$ \\
\hline Potassium (mmol/L) & $4(3.7-4.6)$ & $3.9(3.5-4.3)$ & $<0.001$ \\
\hline CRP (mg/dL) & $6.08(2.4-12.5)$ & $\begin{array}{l}8.07(2.9- \\
16.2)\end{array}$ & 0.020 \\
\hline Haemoglobin (g/dL) & $\begin{array}{l}10.25(8.8- \\
12.0)\end{array}$ & $\begin{array}{l}11.8(10.2- \\
13.2)\end{array}$ & $<0.001$ \\
\hline Platelet $\left(\times 10^{3} / \mu \mathrm{L}\right)$ & $197(119-275)$ & $174(126-226)$ & 0.016 \\
\hline Blood sugar (mg/dL) & $\begin{array}{l}120(97.8- \\
159.3)\end{array}$ & $129(106-162)$ & 0.019 \\
\hline Length of stay in the hospital, median (IQR) & $37(20-92.5)$ & $13(8-27)$ & $<0.001$ \\
\hline Admission to ICU, n (\%) & $46(22.1)$ & 172 (12.7) & $<0.001$ \\
\hline 30-day mortality, n (\%) & $44(21.2)$ & $117(8.6)$ & $<0.001$ \\
\hline 90-day mortality, n (\%) & 69 (33.2) & $177(13.1)$ & $<0.001$ \\
\hline \multicolumn{4}{|c|}{$\begin{array}{l}\text { Abbreviations: IQR, interquartile range; } \mathrm{BMI} \text {, body mass index; } \mathrm{CLABSI} \text {, central line-associated } \\
\text { bloodstream infection; PLABSI, peripheral line-associated bloodstream infection; } \mathrm{SpO}_{2} \text {, oxygen } \\
\text { saturation measured by a pulse oximeter; } \mathrm{Y}-\mathrm{GTP}, \mathrm{Y} \text {-glutamyl transpeptidase; CRP, C-reactive protein. }\end{array}$} \\
\hline
\end{tabular}

Regarding the sources of bacteraemia, pneumonia (32.2\% vs. $2.7 \%$; $<<0.001)$, CLABSI/PLABSI (6.3\% vs. $0.2 \% ; p<0.001)$, and skin and soft tissue infections ( $2.4 \%$ vs. $0.7 \% ; p=0.037)$ were significantly more commonly seen in the PAB group than in the ECB group. The PAB group had higher percentages of a history of hospitalization ( $37.5 \%$ vs. $29.0 \% ; p=0.015)$ and surgery $(42.8 \%$ versus $16.3 \% ; p<0.001)$ and recent usage of steroids (34.6\% versus $14.0 \%$; $p<0.001)$, chemotherapy $(16.3 \%$ versus $9.1 \% ; p=0.003)$, and antibiotics $(82.7 \%$ versus $27.5 \%$; $<<0.001)$ than the ECB group.

The independent associated factors for $\mathrm{PAB}$ that were revealed in the multivariable analysis were as follows: nosocomial infection $(\mathrm{OR}=1.84,95 \% \mathrm{Cl}=1.2-2.8 ; \mathrm{p}=0.006)$, pneumonia $(\mathrm{OR}=4.2,95 \% \mathrm{Cl}=$ $1.92-9.11 ; p<0.001)$, sex (males) $(O R=2.48,95 \% \mathrm{Cl}=1.64-3.76 ; p<0.001)$, exposure to antibiotics within 90 days $(\mathrm{OR}=4.4,95 \% \mathrm{Cl}=2.64-7.46 ; \mathrm{p}<0.001)$, urinary catheterization $(\mathrm{OR}=2.01,95 \% \mathrm{Cl}=1.27-$ 3.19; $p=0.003)$, age $<77$ years $(\mathrm{OR}=1.69,95 \% \mathrm{Cl}=1.11-2.59 ; \mathrm{p}=0.015)$, body mass index $(\mathrm{BMI})<19$ $(\mathrm{OR}=2.42,95 \% \mathrm{Cl}=1.61-3.64 ; \mathrm{p}<0.001)$, presence of central venous catheter $(\mathrm{OR}=2.42,95 \% \mathrm{Cl}=1.11-$ 3.0; $p=0.018)$, and CLABSI/PLABSI $(\mathrm{OR}=15.3,95 \% \mathrm{Cl}=3.09-75.6 ; \mathrm{p}<0.001)$ (Table 2). In addition, urinary tract infection $(\mathrm{OR}=0.34,95 \% \mathrm{Cl}=0.18-0.65 ; \mathrm{p}=0.001)$ and abdominal infection $(\mathrm{OR}=0.47,95 \%$ $\mathrm{Cl}=0.23-0.96 ; \mathrm{p}=0.039)$ were sources of bacteraemia negatively associated with PAB (Table 2). 
Table 2

Results of the multivariable logistic regression analysis used to determine the Non-PSEUDO-AntiBiotiCs score.

\begin{tabular}{|c|c|c|c|c|c|}
\hline & Adjusted OR & Beta coefficient & $95 \% \mathrm{Cl}$ & p values & Points \\
\hline Nosocomial & 1.84 & 0.61 & $1.2-2.8$ & 0.006 & 1 \\
\hline Pneumonia & 4.2 & 1.43 & $\begin{array}{l}1.92- \\
9.11\end{array}$ & $<0.001$ & 3 \\
\hline Sex (male) & 2.48 & 0.91 & $\begin{array}{l}1.64- \\
3.76\end{array}$ & $<0.001$ & 2 \\
\hline $\begin{array}{l}\text { Exposure to antibiotics within } \\
90 \text { days }\end{array}$ & 4.4 & 1.49 & $\begin{array}{l}2.64- \\
7.46\end{array}$ & $<0.001$ & 3 \\
\hline Urinary tract infection & 0.34 & -1.1 & $\begin{array}{l}0.18- \\
0.65\end{array}$ & 0.001 & -2 \\
\hline Urinary catheterization & 2.01 & 0.70 & $\begin{array}{l}1.27- \\
3.19\end{array}$ & 0.003 & 1 \\
\hline AbDOminal Infection & 0.47 & -0.75 & $\begin{array}{l}0.23- \\
0.96\end{array}$ & 0.039 & -1 \\
\hline Age $<77$ & 1.69 & 0.53 & $\begin{array}{l}1.11- \\
2.59\end{array}$ & 0.015 & 1 \\
\hline $\mathrm{BMI}<19$ & 2.42 & 0.88 & $\begin{array}{l}1.61- \\
3.64\end{array}$ & $<0.001$ & 2 \\
\hline $\begin{array}{l}\text { Presence of Central venous } \\
\text { catheter }\end{array}$ & 1.82 & 0.60 & $\begin{array}{l}1.11- \\
3.0\end{array}$ & 0.018 & 1 \\
\hline CLABSI/PLABSI & 15.3 & 2.73 & $\begin{array}{l}3.09- \\
75.6\end{array}$ & $<0.001$ & 5 \\
\hline
\end{tabular}

To develop a prediction system for PAB, we focused on the beta coefficients corresponding to the variables that were statistically significant in the multivariable analysis. We calculated the weight scores by dividing each beta coefficient by the smallest value among the absolute beta coefficients and rounding the divided beta coefficients to develop the understandable rule. The obtained weight scores (Non-PSEUDO-AntiBiotiCs score) are shown as follows: Nosocomial (1 point); Pneumonia (3 points); Sex (males, 2 points); Exposure to antibiotics within 90 days (3 points); Urinary tract infection (-2 points); Urinary catheterization (1 point); abDOminal infection (-1 point); Age < 77 years (1 point); BMI $<19$ (2 points); presence of Central venous catheter (1 point); and CLABSI/PLABSI (5 points).

In the final analysis, the area under the ROC curve was 0.89 (95\% Cl: 0.88-0.92) (Fig. 2), and the best cutoff point was 5 . A score of 5 or higher had a sensitivity of $80 \%$, a specificity of $83 \%$, a positive predictive value of $42 \%$, and a negative predictive value of $96 \%$. 


\section{Discussion}

To the best of our knowledge, this study is the first to develop a clinically predictive (exclusion) score for PAB, "Non-PSEUDO-AntiBiotiCs score", using 11 elements that were significantly different in multivariable analysis. Males, age $<77$ years, $\mathrm{BMI}<19$, placement of the urinary catheter, indwelling central venous catheter, nosocomial infection, use of antibiotics within 90 days, pneumonia, and CRBSI as a source of bacteraemia were independent associated factors for PAB, and the probability of PAB tended to be low if the score was less than 5 . The current study differs from previous studies in that it included larger sample size and provided a simple and useful prediction score in the clinical setting. This scoring system would help clinicians select empirical antibacterial therapy.

It is often difficult for clinicians to decide whether $P$. aeruginosa should be considered in the setting of suspected community-acquired and nosocomial infections, such as pneumonia, urinary tract infection, and intra-abdominal infections. While the failure of empirical treatment in patients with PAB has already been shown to increase the mortality rate [20], abuse of broad-spectrum antimicrobial agents could lead to multidrug-resistant bacteria [5] and increase adverse events, such as Clostridium difficile infections [21], thereby resulting in longer hospital stays and additional costs [22]. Therefore, it is important to select appropriate empirical antimicrobials based on patients' risk factors and clinical findings.

Two previous large studies determined the risk factors for PAB using ECB as a control group and found that an indwelling central venous catheter (CVC) [11], neutropenia [11], presentation with septic shock [11], healthcare-associated infection [11], and respiratory tract infection [8] were independent risk factors. Similarly, the present study also showed that the presence of CVC and respiratory infection were independent factors for $\mathrm{PAB}[8,13]$. In addition, urinary tract infection was found to be one of the negative factors for $P A B$; this finding is consistent with that in a previous study [8].

In comparison to findings in previous studies, one of the new independent associated factors identified in this study was CLABSI/PLABSI. This result could be explained by the fact that $P$. aeruginosa is the most common gram-negative rod causing CLABSI/PLABSI, while E. coli is relatively rare [23, 24]. A previous study showed the above trend, but the finding was not statistically significant [11]. The larger sample size might have contributed to the significant findings in this present study. The current study also showed that $\mathrm{BMI}<19$ was an associated factor for PAB. Because this study was a cross-sectional study, it is unclear whether low BMI is a cause or a consequence of PAB; however, $P$. aeruginosa infection could be a cause of emaciation because chronic infection with $P$. aeruginosa has been reported to produce pyocyanin, which leads to weight loss [25]. In addition, patients with chronic underlying diseases, such as bronchiectasis and cancer, may develop malnutrition [26, 27]. These patients may have contracted $P$. aeruginosa infection during their medical treatment in hospitals. Moreover, the findings of other significant associated factors, including age, male sex [1, 6, 7], exposure to antibiotics [12, 13], and urinary catheterization [12], are consistent with those in previous studies. However, it is possible that some hidden confounding factors could not be identified in the present retrospective study since it 
addressed only cases of recent hospitalization for a period of less than one year, and this could be an issue for future studies.

Since delays in treatment of PAB are known to be associated with increased mortality $[1,20]$, early prediction of PAB may contribute to patients' clinical outcomes. Our scoring system may help clinicians determine whether $P$. aeruginosa should be considered a causative pathogen of infection. Moreover, the use of this scoring system may reduce unnecessary broad-spectrum antimicrobial use, thereby preventing the emergence of multidrug-resistant bacterial pathogens.

This study has several limitations. First, this study was performed at a single institution, and the sample size was relatively small. Second, this was an observational study; thus, it is possible that unknown risk factors were distributed unequally between the two groups. Third, this study included only patients with positive blood cultures. Therefore, this scoring system cannot be applied to all patients with negative blood cultures. Since it is often unclear whether bacteraemia is present in the early onset of the disease, this scoring system should be interpreted expansively and judged carefully together with clinical information. Fourth, this scoring system cannot be used if the source of infections remains unknown at the time of diagnosis because clinicians need to use the source of infection to calculate the score.

\section{Conclusion}

We developed the Non-PSEUDO-AntiBiotiCs score. This scoring system may allow clinicians to rule out the possibility of $P$. aeruginosa bacteraemia and optimize the use of broad-spectrum antimicrobials.

\section{List Of Abbreviations}

CLABSI, Central line-associated bloodstream infection; COPD, chronic obstructive pulmonary disease; CVC, central venous catheter; ECB, E. coli bacteraemia; PAB, Pseudomonas aeruginosa bacteraemia; PLABSI, peripheral line-associated bloodstream infection; ROC, receiver operating characteristic.

\section{Declarations}

\section{Ethics approval and consent to participate:}

The research protocol of this study was approved by the Facility Review Committee of St. Luke's International Hospital, Tokyo (number: 20-J001). This study was conducted in accordance with the Declaration of Helsinki and followed the Strengthening the Reporting of Observational Studies in Epidemiology (STROBE) guidelines. Because this study is based on a retrospective analysis of the routinely obtained data, the requirement for patient agreement was waived by the Facility Review Committee of St. Luke's International Hospital.

Consent for publication: 
Not applicable

\section{Availability of data and materials:}

The datasets used and analysed during the current study available from the corresponding author on reasonable request.

\section{Competing interests:}

The authors declare that they have no competing interests.

\section{Funding:}

The authors did not receive any funding for this study.

\section{Author contributions:}

All authors contributed to the study conception and research design. KI compiled and synthesized the data and drafted the first version of the manuscript. TM, KH, and NM contributed to the writing of the manuscript. $\mathrm{KI}$ and $\mathrm{KH}$ conducted the statistical analysis. All authors were responsible for interpreting the results and approved the final version of the manuscript.

\section{Acknowledgments:}

We would like to thank Editage (www.editage.com) for English language editing.

\section{References}

1. Parkins MD, Gregson DB, Pitout JDD, Ross T, Laupland KB. Population-based study of the epidemiology and the risk factors for pseudomonas aeruginosa bloodstream infection. Infection. 2010;38:25-32.

2. Thaden JT, Park LP, Maskarinec SA, Ruffin F, Fowler VG, van Duin D. Results from a 13-year prospective cohort study show increased mortality associated with bloodstream infections caused by pseudomonas aeruginosa compared to other bacteria. Antimicrob Agents Chemother. 2017;61:111.

3. Lambert PA. Mechanisms of antibiotic resistance in Pseudomonas aeruginosa. J R Soc Med. 2002;95 Suppl 4:22-6.

4. Tschudin-Sutter S, Fosse N, Frei R, Widmer AF. Combination therapy for treatment of Pseudomonas aeruginosa bloodstream infections. PLoS One. 2018;13:1-13.

5. Karam G, Chastre J, Wilcox MH, Vincent J-L. Antibiotic strategies in the era of multidrug resistance. Crit Care. 2016;20:136.

6. Lee CC, Hsieh CC, Lee NY, Chan TY, Hong MY, Chi CH, et al. Different clinical presentation of community-onset bacteremia among neutropenic adults in the ED. Am J Emerg Med. 2015;33:907- 
12.

7. Hernandez C, Cobos-Trigueros N, Feher C, Morata L, De La Calle C, Marco F, et al. Community-onset bacteraemia of unknown origin: clinical characteristics, epidemiology and outcome. Eur $\mathrm{J}$ Clin Microbiol Infect Dis. 2014;33:1973-80.

8. Choi Y, Paik JH, Kim JH, Han SB, Durey A. Clinical predictors of pseudomonas aeruginosa bacteraemia in emergency department. Emerg Med Int. 2018;2018:1-6.

9. Rojas A, Palacios-Baena ZR, López-Cortés LE, Rodríguez-Baño J. Rates, predictors and mortality of community-onset bloodstream infections due to Pseudomonas aeruginosa: systematic review and meta-analysis. Clin Microbiol Infect. 2019;25:964-70.

10. Iversen $B G$, Brantsæter AB, Aavitsland P. Nationwide study of invasive Pseudomonas aeruginosa infection in Norway: Importance of underlying disease. J Infect. 2008;57:139-46.

11. Cheong HS, Kang C-I, Wi YM, Kim ES, Lee JS, Ko KS, et al. Clinical significance and predictors of community-onset Pseudomonas aeruginosa bacteremia. Am J Med. 2008;121:709-14.

12. Schechner V, Nobre V, Kaye KS, Leshno M, Giladi M, Rohner P, et al. Gram-negative bacteraemia upon hospital admission: when should pseudomonas aeruginosa be suspected? Clin Infect Dis. 2009;48:580-6.

13. Hammer KL, Justo JA, Bookstaver PB, Kohn J, Albrecht H, Al-Hasan MN. Differential effect of prior $\beta$ lactams and fluoroquinolones on risk of bloodstream infections secondary to Pseudomonas aeruginosa. Diagn Microbiol Infect Dis. 2017;87:87-91.

14. Aminzadeh Z, Simpson P, Athan E. Central venous catheter associated blood stream infections (CVCBSIs) in the non-intensive care settings: Epidemiology, microbiology and outcomes. Infect Dis Heal. 2019;24:222-8.

15. Ling ML, Apisarnthanarak A, Jaggi N, Harrington G, Morikane K, Thu LTA, et al. APSIC Guide for Prevention of Central Line Associated Bloodstream Infections (CLABSI). Antimicrob Resist Infect Control. 2016;5:1-9.

16. Chopra V, O'Horo JC, Rogers MAM, Maki DG, Safdar N. The risk of bloodstream infection associated with peripherally inserted central catheters compared with central venous catheters in adults: a systematic review and meta-analysis. Infect Control Hosp Epidemiol. 2013;34:908-18.

17. Ishikane M, Hayakawa K, Kutsuna S, Takeshita N, Ohmagari N. Epidemiology of blood stream infection due to Candida species in a tertiary care hospital in Japan over 12 years: Importance of peripheral line-associated candidemia. PLoS One. 2016;11:e0165346.

18. Tsuboi M, Hayakawa K, Mezaki K, Katanami Y, Yamamoto K, Kutsuna S, et al. Comparison of the epidemiology and microbiology of peripheral line- and central line-associated bloodstream infections. Am J Infect Control. 2019;47:208-10.

19. Friedman ND. Health care-associated bloodstream infections in adults: a reason to change the accepted definition of community-acquired infections. Ann Intern Med. 2002;137:791.

20. Cheong HS, Kang C-I, Wi YM, Ko KS, Chung DR, Lee NY, et al. Inappropriate initial antimicrobial therapy as a risk factor for mortality in patients with community-onset Pseudomonas aeruginosa 
bacteraemia. Eur J Clin Microbiol Infect Dis. 2008;27:1219-25.

21. Chalmers JD, Al-Khairalla M, Short PM, Fardon TC, Winter JH. Proposed changes to management of lower respiratory tract infections in response to the Clostridium difficile epidemic. J Antimicrob Chemother. 2010;65:608-18.

22. Webb BJ, Sorensen J, Jephson A, Mecham I, Dean NC. Broad-spectrum antibiotic use and poor outcomes in community-onset pneumonia: a cohort study. Eur Respir J. 2019;54:1900057.

23. Surapat B, Montakantikul P, Malathum K, Kiertiburanakul S, Santanirand P, Chindavijak B. Microbial epidemiology and risk factors for relapse in gram-negative bacteria catheter-related bloodstream infection with a pilot prospective study in patients with catheter removal receiving short-duration of antibiotic therapy. BMC Infect Dis. 2020;20:1-12.

24. Gupta S, Mallya SP, Bhat A, Baliga S. Microbiology of non-tunnelled catheter-related infections. J Clin Diagnostic Res. 2016;10:DC24-8.

25. Larian N, Ensor M, Thatcher SE, English V, Morris AJ, Stromberg A, et al. Pseudomonas aeruginosaderived pyocyanin reduces adipocyte differentiation, body weight, and fat mass as mechanisms contributing to septic cachexia. Food Chem Toxicol. 2019;130:219-30.

26. Olveira G, Olveira C, Gaspar I, Porras N, Martín-Núñez G, Rubio E, et al. Fat-free mass depletion and inflammation in patients with bronchiectasis. J Acad Nutr Diet. 2012;112:1999-2006.

27. Lidoriki I, Schizas D, Frountzas M, Machairas N, Prodromidou A, Kapelouzou A, et al. GNRI as a prognostic factor for outcomes in cancer patients: a systematic review of the literature. Nutr Cancer. 2021;73:391-403.

\section{Figures}




\section{P. aeruginosa or $E$. coli detected in blood cultures$$
(\mathrm{n}=1592)
$$

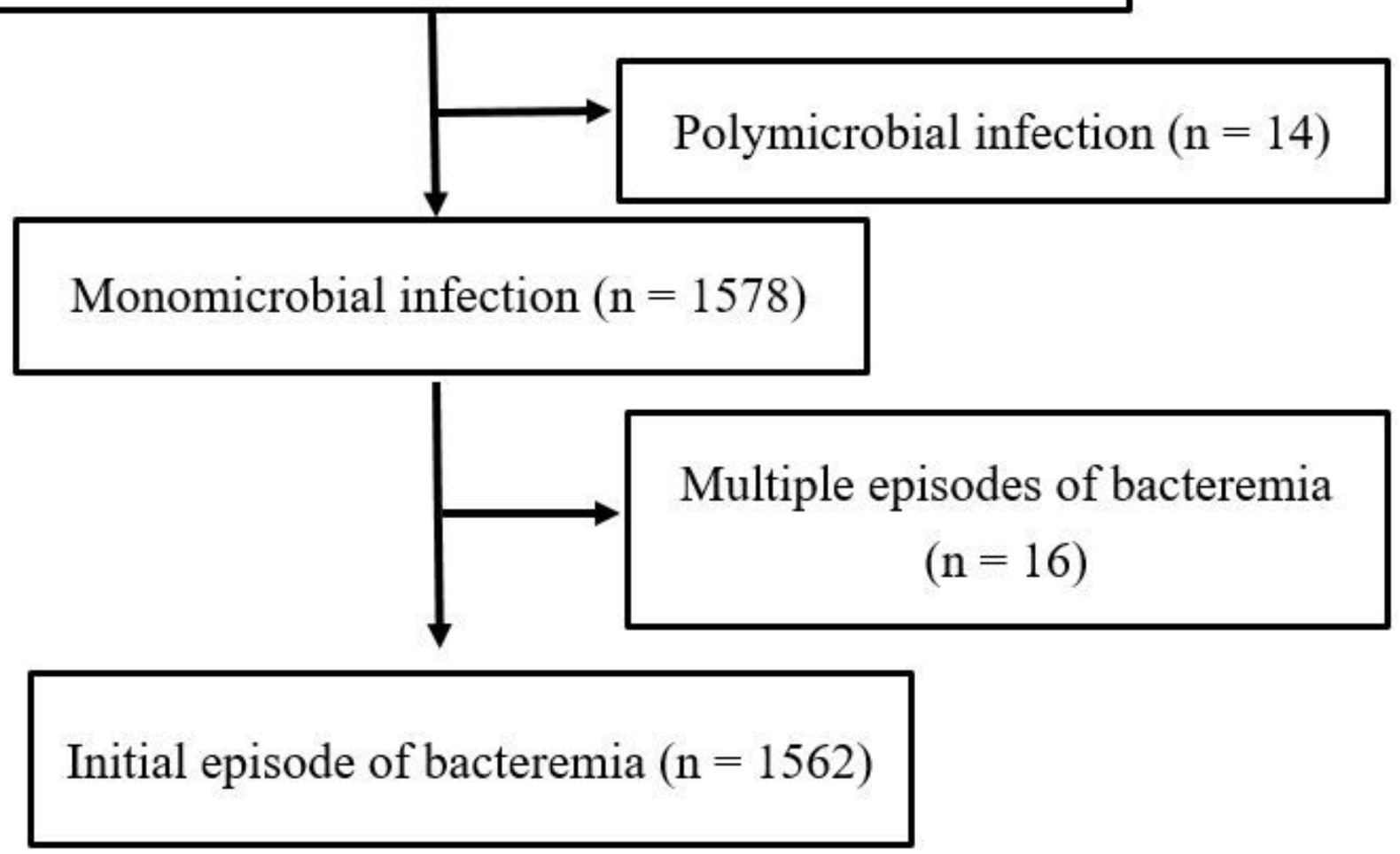

Figure 1

Study design Of the 1592 observations, 14 observations (7 patients with both PAB and ECB) were excluded, and the first episodes of bacteraemia of 16 patients with multiple episodes of bacteraemia were included. Consequently, 1562 patients (208 PAB and 1354 ECB) were included in the study. Abbreviations: P. aeruginosa, Pseudomonas aeruginosa; E. coli, Escherichia coli; PAB, Pseudomonas aeruginosa bacteraemia; ECB, E. coli bacteraemia. 


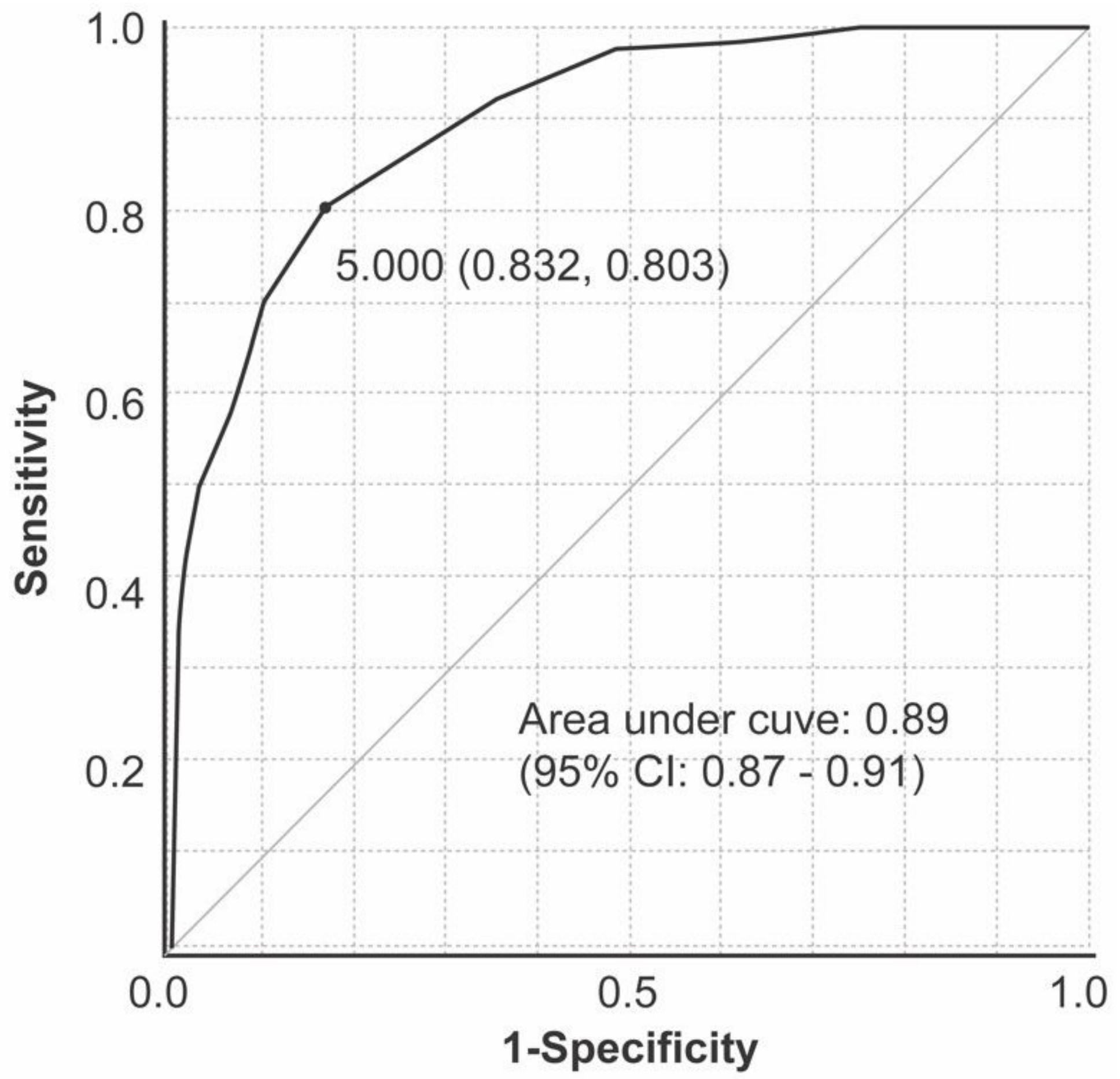

Figure 2

The receiver operating characteristic curve of the Non-PSEUDO-AntiBiotiCs score In the final analysis, the area under the receiver operating characteristic curve was 0.89 (95\% Cl: 0.88-0.92), and the best cut-off point was 5 . A score of 5 or higher had a sensitivity of $80 \%$, a specificity of $83 \%$, a positive predictive value of $42 \%$, and a negative predictive value of $96 \%$. 